
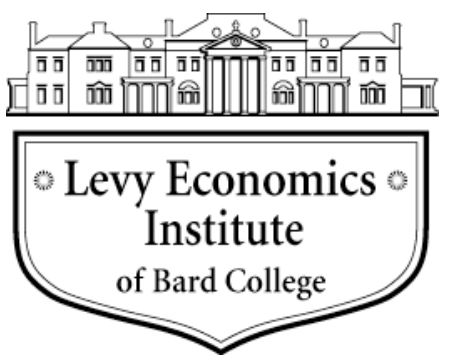

Working Paper No. 690

\title{
The Measurement of Time and Income Poverty
}

by

\author{
Ajit Zacharias* \\ Levy Economics Institute of Bard College
}

October 2011

*The author is grateful to Thomas Masterson, Kijong Kim, and Rania Antonopoulos for their comments and suggestions.

The Levy Economics Institute Working Paper Collection presents research in progress by Levy Institute scholars and conference participants. The purpose of the series is to disseminate ideas to and elicit comments from academics and professionals.

Levy Economics Institute of Bard College, founded in 1986, is a nonprofit, nonpartisan, independently funded research organization devoted to public service. Through scholarship and economic research it generates viable, effective public policy responses to important economic problems that profoundly affect the quality of life in the United States and abroad.

Levy Economics Institute

P.O. Box 5000

Annandale-on-Hudson, NY 12504-5000

http://www.levyinstitute.org

Copyright (C Levy Economics Institute 2011 All rights reserved 


\begin{abstract}
Official poverty thresholds are based on the implicit assumption that the household with poverty-level income possesses sufficient time for household production to enable it to reproduce itself as a unit. Several authors have questioned the validity of the assumption and explored alternative methods to account for time deficits in the measurement of poverty. I critically review the alternative approaches within a unified framework to highlight the commonalities and relative merits of individual approaches. I also propose a two-dimensional, time-income poverty measure that accounts for intrahousehold disparities in the division of household labor and briefly discuss its uses in thinking about antipoverty policies.
\end{abstract}

Keywords: Time Poverty; Household Production; Gender Disparities

JEL Classifications: B54, I32, J16, J22 


\section{INTRODUCTION}

The purpose of this paper is to represent the major existing approaches to time and income poverty within a unified framework. As will be obvious, this purpose has compromised certain subtle aspects of the various approaches. However, my hope is that the framework captures the essential aspects of the different contributions. I also propose a modification to the standard time-income poverty measure to account for intrahousehold disparities.

\section{A TWO-DIMENSIONAL MEASURE OF POVERTY}

I choose the week as the unit of time so that the total number of hours is fixed at $168(=24 \times 7)$. I also restrict my attention to a household with a single worker so as to avoid, for now, dealing with the intrahousehold allocation of time. I begin by defining the time available to the household $(A)$ for income-generation ${ }^{1}$ and "leisure" ${ }^{2}$, after setting aside: (a) the minimum required amount of time for personal care $(\bar{C})$, (b) the minimum required amount of nonsubstitutable time for household production $(\bar{D})$, and (c) the amount of essential substitutable household production time $(\bar{R})$ required to subsist at the poverty-level of income. Substitutable time represents the time that can be replaced by the purchase of market substitutes by the household.

$$
A=168-\bar{C}-\bar{D}-\bar{R}
$$

The symbols on the right hand side of the equation are adorned with the bar (-) because they represent the "norms" for the group that the household belongs to rather than the actual observed values for the household. They are the time allocation parameters for the household which, in principle, are similar to the parameters (such as minimum expenditures on food and nonfood items) used in the construction of income/consumption poverty measures.

Time deficit or surplus $(X)$ is defined as the excess or deficiency of hours of incomegenerating activity $(L)$ in relation to available time:

\footnotetext{
${ }^{1}$ Income-generating activities can involve working for wage and own-account work.

${ }^{2}$ We put the term leisure in quotes here because it is used here as a catch-all for the time available for all activities other than income-generation, household production, and personal care. Such activities can include, in addition to "pure leisure," learning, community activities, political/social activism, etc.
} 


$$
X=A-L
$$

The Vickery modification to the standard income-poverty threshold is based on the notion that the time deficit represents an uncompensated loss in necessary household production for employed individuals (Vickery 1977). The time deficit is valued using the unit price $(p)$ of market substitutes for household production. Denoting the standard poverty threshold for the household as $\tilde{y}$ and the Vickery threshold as $y^{o}$, I can write:

$$
y^{o}=\tilde{y}-\min (0, X) p
$$

To attain the poverty-level of consumption, the household has to combine a certain amount of money with a certain amount of time spent on household production. Consider two households that are identical in all respects, $A$ and $B$, who also happen to have an identical amount of money income. Suppose that one household, $A$, does not have enough time available to devote to the necessary amount of household production while the other household, $B$, has the necessary available time. To treat the two households as equally income-poor or nonpoor would be inequitable toward $B$. The latter's money income (or its poverty threshold) will have to be adjusted by an amount that represents the replacement cost of the foregone household production associated with its time deficit.

The standard and Vickery poverty thresholds coincide if the household has no time deficit. The two-dimensional poverty measure states that the household is poor if its income, denoted as $y$ is less than the Vickery threshold $y^{o}$ or if the household has a time deficit. That is,

$$
y<y^{o} \quad \text { or } \quad X<0
$$

\section{FULL-TIME WORK}

Vickery (1977) chose to evaluate poverty under the hypothetical scenario where all individuals could work full-time and income consisted only of wage income. That is,

$$
L=L^{f}
$$

where $L^{f}$ indicates hours of full-time work. The time deficit associated with full-time work is: 


$$
X=X^{f}=A-L^{f}
$$

The equation for income is:

$$
y=y^{f}=w L^{f}
$$

where the superscript $f$ indicates full-time work and $w$ the hourly wage rate. ${ }^{3}$ Under these assumptions, the household is poor if

$$
y^{f}<y^{o} \text { or } \quad X^{f}<0
$$

An advantage of the framework is that it helps identify individuals who would be poor even if they could work full-time.

\section{ACTUAL WORKING TIME AND ACTUAL INCOME}

Harvey and Mukhopadhyay (2007) evaluated poverty under the actually observed working time and income. That is,

$$
L=L^{a}
$$

where $L^{a}$ indicates actual hours of employment. The associated time deficit is:

$$
X=X^{a}=A-L^{a}
$$

The equation for income is simply:

$$
y=y^{a}
$$

where the superscript $a$ indicates the actual value. Under these assumptions, the household is poor if

$$
y^{a}<y^{o} \quad \text { or } \quad X^{a}<0
$$

\footnotetext{
${ }^{3}$ We leave aside here questions related to the determination of the wage rate associated with full-time work for those who are currently working and not working.
} 


\section{VICKERY AND HM: A COMPARISON}

Suppose that the point labeled $Z$ in the figure represents the observed situation of the household. The Harvey and Mukhopadhyay (HM) method will tell us that the household is income-poor according to the standard income threshold $(\mathrm{YO})$ and time-nonpoor because their actual hours of employment are less than their available time $(A)$. The Vickery method would show, on the basis of the assumed wage rate, that the household would be at point $D$ if it was employed fulltime $(L f)$ - a situation in which they are time-poor, but income non-poor according to the standard income threshold. However, their income poverty status according to the Vickery threshold (see equation (3)) depends on the replacement cost of household production relative to their wage. If the replacement cost is higher than the wage then they would be income-poor. This situation can be seen by comparing the line segments $C D 1$ (representing the Vickery threshold) and $C D$. The household cannot work itself out of poverty because the additional income that it earns by working an additional hour beyond $A$ is less than the replacement cost of the foregone amount of household production. Comparison of the line segments CD2 (representing the Vickery threshold) and CD shows the opposite situation, where the replacement cost is lower than the wage.

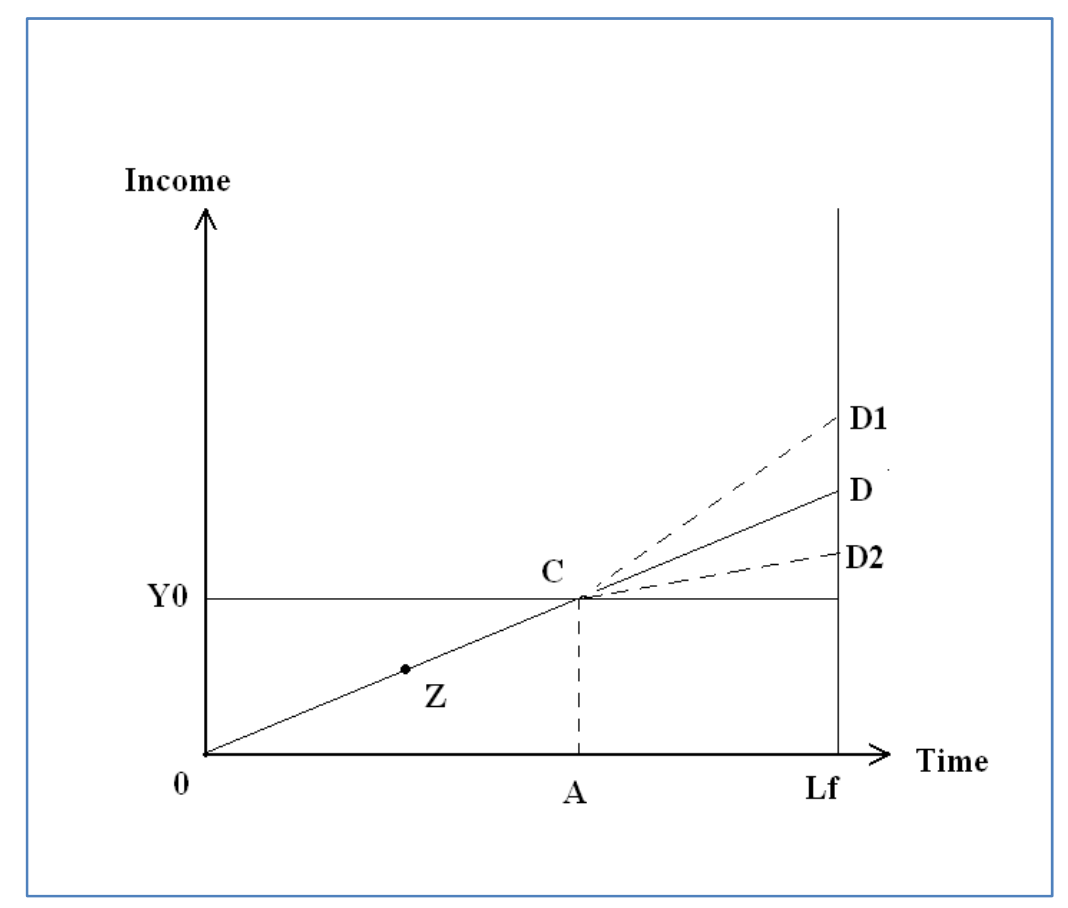

Figure 1 Time and income poverty with actual and full-time hours of employment 


\section{POTENTIAL TIME DEFICIT/SURPLUS WITH NO INCOME-DEFICIT}

There exist a large number of studies that measure and discuss the "time-crunch" phenomenon. In an influential contribution, Goodin et al. (2005) argued that most of that literature is somewhat misguided because it fails to compare the actual amounts of time spent by individuals on unpaid work, paid work, and personal care against their respective thresholds. I interpret the thresholds specified above (see equation (1)) as representing, at least in spirit, the thresholds for personal care and household production postulated by Goodin et al. Analogously, they define the amount of necessary time in employment as "putting in enough paid hours to get your income up to the poverty-level"(p.50). That is,

$$
L=L^{\prime}=\tilde{y} / w
$$

where $L^{\prime}$ indicates the hours of employment required to earn the poverty-level of income. ${ }^{4}$ The associated time deficit, which corresponds to the Goodin et al definition of "discretionary time," is:

$$
X=X^{\prime}=A-L^{\prime}
$$

Income is, by assumption, set equal to the standard poverty threshold:

$$
y=\tilde{y}
$$

The household is considered time-poor or under time-crunch if

$$
X^{\prime}<0
$$

Unlike the earlier two scenarios, this approach does not yield a two-dimensional measure. Instead, what emerges from the analysis is a time-poverty measure that seeks to adjust for differential wage rates. ${ }^{5}$

\footnotetext{
${ }^{4}$ Goodin et al. estimated a regression equation for the wage, conditional on the hours of employment and demographics, to account for the potential dependence of wage on the hours of employment. The threshold values for the wage and hours of employment were determined using an iterative procedure.

${ }^{5}$ Goodin et al. defined discretionary time as the residual left after subtracting the necessary time for paid work, personal care, and household production. Poverty in discretionary time was defined in purely relative terms.
} 


\section{POTENTIAL INCOME WITH NO TIME DEFICIT}

Instead of asking what the amount of discretionary time would be if the household's hours of employment were just enough hours to earn the poverty-level of income, one could ask what the amount of income would be if the household with a time deficit cut back its hours of employment to eliminate such deficit. If the household has no time deficit, then its income would be calculated using its actual hours of employment. Thus, the hours of employment are given by:

$$
L=L^{\prime \prime} \begin{cases}=A, & \text { if } X^{a}<0 \\ =L^{a}, & \text { if } X^{a} \geq 0\end{cases}
$$

The associated (labor) income is:

$$
y=y^{\prime \prime}=w L^{\prime \prime}
$$

The household is considered time-poor if

$$
y^{\prime \prime}<\tilde{y} \text { and } \quad X^{a}<0
$$

This definition of time-poverty captures the spirit of the notion of Bardasi and Wodon (BW) that the time-poor are those with a time deficit and "belong to households that are poor or would be poor if individuals were to reduce their working hours up to the time-poverty line" (Bardasi and Wodon 2009, p.7). ${ }^{6}$

\section{GOODIN ET AL. AND BW: A COMPARISON}

In Figure 2 below, suppose that the actual situation of the household is at point $M$. The hours of employment, $L$, exceed the available time $A$ and hence the household is time-poor. However, their income at that level of employment is above the standard poverty line, and hence the household is income-nonpoor. The Goodin et al. approach involves a thought experiment in which we find the hours of employment that is just enough to earn a poverty-level of income: point $M 1$ in the figure represents such a situation for the household, accompanied by a time deficit (negative "discretionary time"). In contrast, the BW approach calculates the hypothetical level of income consistent without any time deficit and compares it against the income-poverty

\footnotetext{
${ }^{6}$ Bardasi and Wodon defined (unadjusted) time-poverty in terms of total, i.e., the sum of paid and unpaid work time. The definition that I discuss is a version of this definition, focusing only on paid work. 
threshold. The point $M 2$ represents such a situation, where the household has reduced its hours of employment from $L$ to $A$. However, such a reduction makes it income-poor, thus making it time-poor as per the BW definition (see equation (19)).

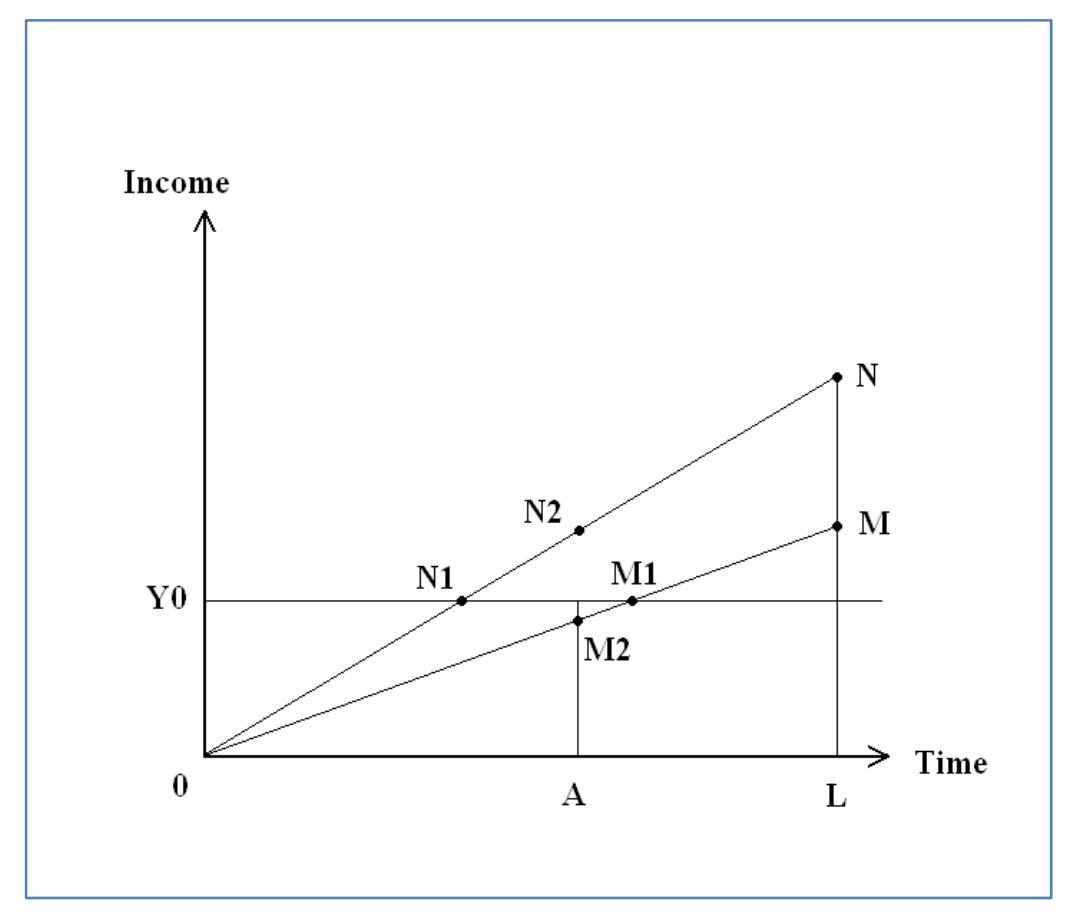

Figure 2 Discretionary time and income-poverty

To illustrate the role of the wage in determining the outcomes under both approaches, I have also shown the scenario under a higher wage rate. Compared to the actual situation, now assumed to be represented by the point $N$, the Goodin et al. method would indicate that the household could reduce its hours of employment (point N1) and avail a positive amount of discretionary time, while the $\mathrm{BW}$ approach would, by comparing points $N 2$ and $N$, conclude that the household is not time-poor.

The figure also illustrates the similarity between the two approaches. The "critical" wage in both is the wage that would allow the household to earn the poverty-level income by being employed for just the time available (A). Geometrically, the critical wage is represented by the slope of the line that passes through the intersection of $A$ and $Y 0$ (income-poverty threshold). The household that is time-poor according to the HM definition would be considered time-poor (nonpoor) by BW and Goodin if the wage faced by the household is lower (higher) than the critical wage. 


\section{POTENTIAL FREE TIME AND INCOME}

Tania Burchardt (2009) modified the standard time deficit equation that I have used so far by incorporating the consideration that households with sufficient income can replace the necessary amount of household production associated with $R$ (see equation (1)) with market substitutes, irrespective of whether they have a time deficit, thus enhancing the amount of free time that they can obtain. ${ }^{7}$ A fuller treatment of Burchardt's approach can be found in the Appendix. Denoting the amount of time replaced by market substitutes as $B$, free time $S$ can be written as:

$$
S=X+B=A-L+B
$$

The amount of time that can be replaced cannot, obviously, exceed $R$. It also makes sense to assume that the expenses of replacement are incurred after meeting the poverty-level consumption needs. Hence:

$$
B \begin{cases}=\min (R,(y-\tilde{y}) / p) & \text { if } y \geq \tilde{y} \\ =0 & \text { if } y<\tilde{y}\end{cases}
$$

Income available to the household is expressed net of the replacement cost of household production:

$$
y^{\prime}<y-p B
$$

The associated two-dimensional poverty measure would consider the household as poor if the income net of the replacement cost of household production is below the standard income threshold or if the free time is negative:

$$
y^{\prime}<\tilde{y} \quad \text { or } \quad S=0
$$

Alternatively, a composite index that may be called the "time-income capability index" (TI) could be defined: ${ }^{8}$

\footnotetext{
${ }^{7}$ Burchardt also included the possibility of help from outside of the household and government-provided help, issues that we consider later.

${ }^{8}$ Burchardt took into account the potential of being employed for alternative number of hours (i.e., alternative values of $L$ ) and replacing different amounts of household production (alternative values of $B$ ) in defining the index. I am presenting a simpler version of her approach that facilitates a straightforward comparison with the other approaches.
} 


$$
T I=f\left(y^{\prime}, S\right)
$$

The contrast between this approach and that of BW and Goodin et al. can be seen by considering the situation when the household is time-poor but income-nonpoor. Both BW and Goodin would consider the household as time-poor only if its potential income from working available hours $(A)$ falls below the standard income threshold. My adaptation of the Burchardt approach would consider the same household as time-poor only if its current income does not allow the household to "buy out" the time deficit without falling into income-poverty. The replacement cost of household production plays no role in the analysis of BW and Goodin et al; the time-poverty status of the household depends only on its wage rate. Burchardt's approach, as in the earlier Vickery and HM approaches, conceptualizes the time-poverty (and incomepoverty) status as dependent on the household's income (wage rate) and the replacement cost of household production.

The relationship between income (wage rate) and replacement cost is illustrated in Figure 3. Suppose that the actually observed situation of the household is that of time-poverty, the extent of which is indicated by the distance on the horizontal axis between 0 and $X$. Hypothetical income levels associated with that extent of time-poverty are shown by the points labeled $Y 1, Y 2$, and $Y 3$ where the higher income levels are assumed to result from higher wage rates. ${ }^{9}$ All income levels shown are above the standard income-poverty threshold, indicated by the line $Y 0 Y 0$, but the lowest income level is below the Vickery threshold indicated by the line $Y^{\prime} 0 Y^{\prime} 0$. The distance between the two thresholds is the monetized value of the time deficit, $|p X|$.

\footnotetext{
${ }^{9} \mathrm{We}$ are assuming here a positive and monotonic relationship between the wage rate and income.
} 


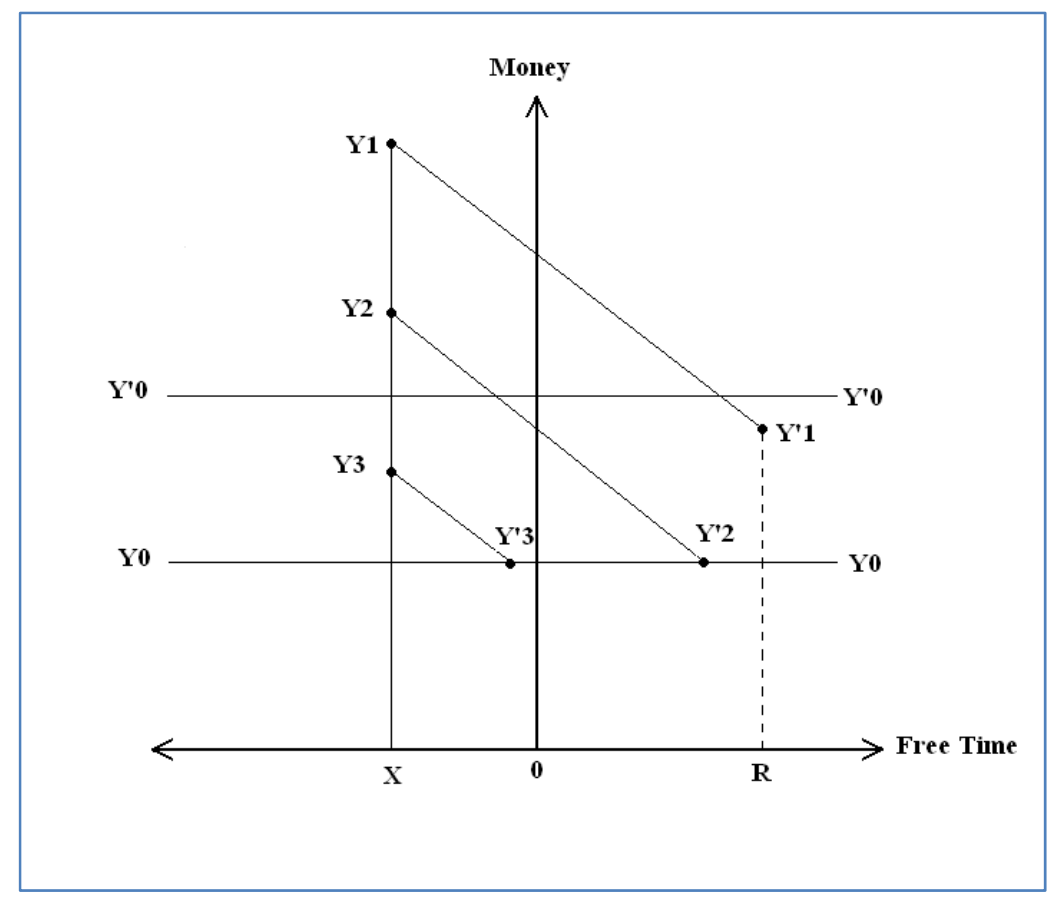

Figure 3 Potential free time and income

At the lowest level of income (wage rate), the maximum amount of time deficit that can be "bought off" by the household without falling below the standard income-poverty threshold would still leave it in a situation of time-poverty. Instead, if the household were to have the intermediate level of income (wage rate) then it would, according to the logic of equations (19)-(21), end up in the situation labeled ( $\left.Y^{\prime} 2\right)$ with the poverty-level of income and some amount of free-time. The highest level of income (wage rate) shown in the figure would allow the household to enjoy the maximum free time possible $(R)$ and a higher-than poverty level of income, as represented by point (Y’3).

\section{INTRAHOUSEHOLD DISPARATIES}

The discussion so far has been confined to the household consisting of a single person (or, more precisely, a single employable individual). Admittedly, the concept of poverty becomes more complicated in a multi-person household, especially because there are well-entrenched social and economic inequalities between the persons. Both theoretical and practical difficulties are introduced by these considerations for the measurement of income-poverty. They revolve around the definitions of the income available to the person and the person's ability to attain the poverty-level of consumption. A household is, by definition, a unit in which there is pooling of 
income and sharing of consumption among its members, though the degrees of pooling and sharing are hard to determine unambiguously. ${ }^{10}$ It is difficult to justify, in principle, why we would consider a single woman with an annual income of $\$ 20,000$ to be richer than a married, nonworking wife with zero personal income, but a household income of $\$ 100,000$. On the other hand, the wives in two married couple households with a poverty-level of income may not be equally nonpoor if the wife in one household is systematically discriminated in terms of consumption. The inability to categorically define the income and consumption available to each person in a household has, for better or worse, favored the choice of the household or family as the unit of analysis in the measurement of income-poverty.

Curiously, Vickery (and, later Douthitt (2000) and HM) accepted the household as the unit of analysis in the development of the two-dimensional measure of poverty. The type of difficulties that prevented the choice of the person as the unit of analysis in the measurement of income-poverty does not apply in the measurement of time-poverty. Unlike income or consumption, the individuals in the household cannot pool or share their time. It is perfectly feasible to choose the household as the unit of analysis in the income-dimension and the individual as the unit of analysis in the time-dimension. The two-dimensional poverty measure constructed in such a manner can be presented in terms of individuals and households. ${ }^{11}$

Interhousehold comparisons of time-poverty that does not take into account the intrahousehold disparities in the division of domestic labor and paid labor can be fundamentally inequitable toward the individuals in the households. The equity argument here is identical to how the neglect of intrahousehold inequality in consumption or income biases the measurement of poverty. Consider two households that are identical in all respects, $A$ and $B$, who also happen to possess the same amount of money income and the same amount of available time. The household $A$ is "egalitarian" in the sense that the division of domestic labor and paid labor among its members does not result in time deficit for any of its members. On the other hand, the household $B$ is non-egalitarian and at least one of its members ends up with a time deficit,

\footnotetext{
${ }^{10}$ A voluminous body of work exists on this topic. For a recent overview and references, see Quisumbing (2004), Chapter 1 and Part 1.

${ }^{11}$ A generally accepted definition of the unit of analysis is the group of "people whose economic resources are to be pooled in determining poverty status" (Citro and Michael 1995). The report just cited also makes the distinction between the unit of analysis and the unit of presentation. The latter refers to the unit in terms of which poverty statistics can be presented. Thus, though the unit of analysis in poverty measurement may be the household, poverty rates can be presented for different groups of people such as children.
} 
defined as the amount by which their hours of employment exceed the time that they have available. Defining the two households as equally time-nonpoor is inequitable toward the individuals in household $B$ who actually face the time deficit.

The adoption of the household as the unit of measurement in the Vickery-type measure obfuscates the disparities in the division of available time among the members of the household. Consider the situation depicted in Figure 5 for a household that is on the time-poverty threshold according to the household-level definition, i.e., their available hours is exactly equal to the hours of employment $(L=A)$. The household is assumed to consist of two employable adults, a man and a woman. The hours of employment and income for each of them and for the household as a whole are shown by the distinct markers in the time-income space. ${ }^{12}$ The hours available to the woman (A1) is less than her hours of employment (L1) and she is therefore timepoor according to the individual-level definition of time-poverty. On the other hand, the man is employed for an amount of time (L2) that does not exceed the time available to him (A2) and is therefore time-nonpoor.

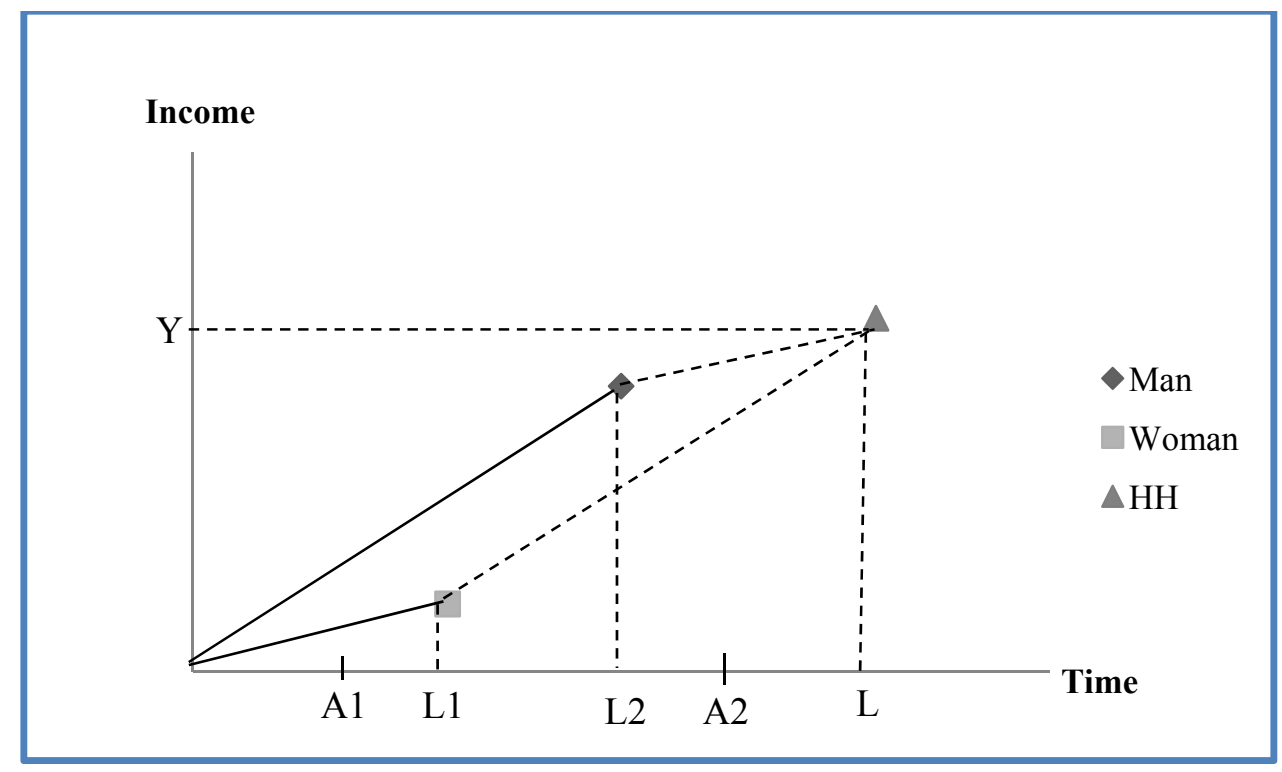

Figure 4 Time-nonpoor household with a time-poor woman

An example could be constructed for the household depicted in Figure 5 to show the case of "the time-nonpoor household with a time-poor man." In this case, perfect equality in the division of available time is assumed, but the hours of employment for the man are supposed to

${ }^{12}$ As before, we are assuming that wages are the only source of income. 
exceed the time available to him. Such a situation can be visualized using Figure 5, by switching the positions of (A1) and (A2) on the horizontal axis and making the necessary revisions to the coordinates of the parallelogram. Both examples illustrate the problem with the household-level measure of time deficit constructed according to the Vickery approach: It can hide the time deficits faced by individuals because it fails to take into account the intrahousehold disparities in the division of domestic and paid labor.

The shift from the household to the individual as the unit of analysis in the measurement of time-poverty necessitates a change in the Vickery definition of time poverty. Instead of designating the household as time-poor if its hours of employment exceed the available time, we should designate the household as time-poor if the hours of employment exceed the available time for at least one of its members. The modified definition can be stated formally with minor modifications to equations (1) and (2). As before, I consider the minimum required time for household production $(\bar{D})$ and time for household production required for subsistence at the poverty-level of income $(\bar{R})$ as household-level parameters. I also assume that the minimum time required for personal care $(\bar{C})$ is the same for all employable adults. The time available to adult $i$ in the household is:

$$
A_{i}=168-\bar{C}-\alpha_{i} \bar{D}-\gamma_{i} \bar{R}
$$

where the parameters $\alpha$ and $\gamma$ indicate the shares of the individual in, respectively, the minimum required time for household production and time for household production required for subsistence at the poverty-level of income. Time deficit or surplus for the individual is given by:

$$
X_{i}=A_{i}-L_{i}
$$

where $L_{i}$ indicates the individual's hours of employment. The modified definition of the time deficit faced by the household with $n$ individuals is:

$$
X^{\prime}=\sum_{i=1}^{n} \min \left(0, X_{i}\right)
$$

Unlike the earlier specification, the above equation sets the value of time deficit for timenonpoor households to zero, thereby ignoring the disparities that would exist among such households in the free time available to them. However, such disparities did not play any role in 
the definition of the Vickery threshold for income poverty. Neither do such disparities matter in drawing the line between the time-poor and the time-nonpoor.

A logical corollary of the new definition of time-poverty is that the Vickery threshold for income poverty would have to be modified. The modification takes into account the replacement cost of the foregone amount of household production that accompanies the time deficit of the individual(s) in the household. Instead of the earlier definition of time-poverty, we should now use the definition that takes into account intrahousehold time deficits (equation (27)):

$$
y^{\prime}=\tilde{y}-X^{\prime} p
$$

When revised to account for the intrahousehold disparities, the two-dimensional poverty measure would designate the household as poor if its income is less than the modified Vickery threshold $y^{\prime}$ or if any of its members have a time deficit. That is,

$$
y<y^{\prime} \quad \text { or } \quad X^{\prime}<0
$$

For the individual in the household, the two-dimensional poverty measure would deem her to be poor if the income of the household that she belongs to is less than the modified Vickery threshold $y^{\prime}$ or if she has a time deficit:

$$
y<y^{\prime} \quad \text { or } \quad X_{i}^{\prime}<0
$$

The revised two-dimensional measure can be presented in terms of individuals and households.

\section{SOME POLICY IMPLICATIONS}

The standard approach of poverty alleviation via income transfers can be applied in the context of the household that is income-poor according to the Vickery threshold (see equation (3)). All that is required is an income transfer equal to or greater than the poverty gap $\left(y^{o}-y\right)$ to enable the household to escape income-poverty. However, such a policy might not be effective or desirable by itself.

The effectiveness of the income-transfer policy depends on the ability of the household to obtain the market substitutes with the amount that it receives. This is possible only if the 
relevant market exists in an accessible manner for the household. In other instances, the market might exist, but it may be impossible for the household to obtain the requisite amount of substitutes at the price that is implicit in the transfer. The problems of missing and imperfect markets can compromise the effectiveness of an anti-poverty strategy that relies solely on income transfers. Such problems are likely to be quite significant in several situations, e.g., the rural developing world and segregated pockets of poverty with relatively high levels of social exclusion in the industrialized world. Direct public provisioning or publicly-financed community provisioning of the wants currently met via self-provisioning would be a far more effective anti-poverty strategy in these contexts (see Antonopoulos and Memis 2010).

An implicit assumption behind relying solely on the income-transfer strategy is that the observed level of the household's hours of employment and its wage rate should be "left alone," irrespective of whether it is acceptable to the household itself or socially. Consider the situation depicted in the figure below of three hypothetical households, all of them income- and timepoor. For simplicity, I assume that they face the same wage rate and have the identical amount of time available, labeled $A$ as in the previous figures. Suppose that the household that is employed full-time $(L f)$ is doing exactly the desired amount of paid work. An income transfer that is at least equal to the vertical distance between the lines $Y$ and $Y^{\prime} 0$ at $L f$ should, in principle, allow it to escape time and income-poverty because the transfer enables it to purchase the requisite market substitutes. 


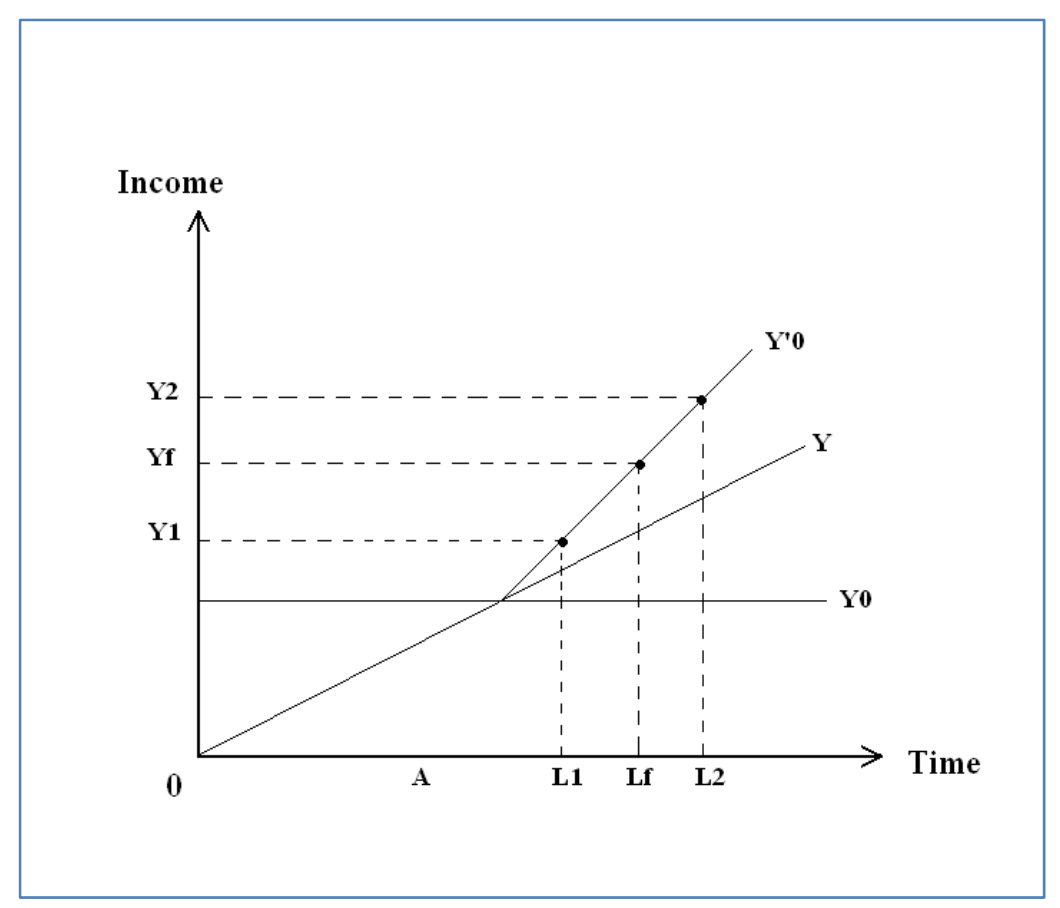

Figure 5 Potential inadequacies of income-transfers

Now, suppose that the other two households, employed respectively, less than full-time, i.e., under-employed (L1) and working overtime (L2), are not working the amount of hours that is desirable. While it is true that the appropriate amount of income transfers can eliminate the time and income-poverty faced by the two households, this may not represent the desirable policy in itself. Underemployment and overwork imposes its own human, economic, and social costs. The two-dimensional measure of poverty discussed here can be used to identify the households that may suffer such vulnerabilities and encourage a closer examination of the causes of underemployment and overwork. Nevertheless, an essential component of antipoverty strategy for such vulnerable households would be the creation of jobs that pay living wages.

\section{CONCLUSION}

In sum, the Vickery and Harvey-Mukhopadhyay approaches appear to be the most pertinent for examining the income-time nexus for the segment of the population that is below or near the income-poverty threshold. The use of the Vickery threshold enables the identification of the "hidden poor"- those who might be income-nonpoor according to the standard threshold, but actually poor when the necessary replacement costs of household production are taken into 
account. The approaches of both Goodin et al. and Bardasi and Wodon result in modified measures of time-poverty alone, with no implications for rethinking income-poverty or the timeconstraints faced by the working poor. Income-poverty rate as measured by the modified Burchardt model specified above will also be identical to the income-poverty rate calculated using the standard income-threshold and lower than the rate implied by the Vickery threshold. Consider a household that is time-poor and income-poor according to the Vickery threshold but not income-poor according to the standard threshold. This household will not be income-poor in the modified Burchardt model because the household can spend only the amount left after meeting the poverty-level consumption needs on buying out the time deficit. It will, however, remain time-poor because it does not have enough disposable income to buy out the time deficit.

These considerations do not imply that modified measures of time-poverty are useless. Comparing the alternatives presented above, it seems to me that the argument that the notion of time-poverty should reflect the differential capacity of households to remedy such poverty by purchasing market substitutes (as recognized by Burchardt) is stronger than the argument that the notion of time-poverty should reflect the "capacity" of households to choose its hours of employment (as in Goodin et al. and Bardasi and Wodon). Typically, in a capitalist economy, the worker has more freedom to spend their money in the manner they choose than to choose the hours of employment of their liking. This suggests that the Burchardt model presented above or some variant thereof may be fruitfully used in identifying the "genuinely" time-poor among the income-nonpoor households. 


\section{APPENDIX}

\section{Introduction}

The purpose of this appendix is to propose a formal framework for the time-income capability measure put forward by Tania Burchardt. ${ }^{13}$ Since my aim is to translate the core ideas into a tractable form, I have not bothered to deal with issues that, in my judgment, can complicate matters significantly but not radically alter the basic model sketched below.

There are three key assumptions made in what follows. First, wages are the only source of household income. Second, the wage remains constant, irrespective of hours worked. Third, the replacement cost of household production remains constant, irrespective of the hours replaced and the income of the household. I consider the household with a single adult in order to abstract from issues related to the intrahousehold allocation of time.

\section{Time-income Capability Set}

The time-income capability set of the household is the list of all potential pairs of free time and income denoted as $\mathbb{Z}=\left\{S_{i j}, y_{i j}\right\}$ where the subscript $i$ is used to denote elements of the set of possible hours of employment (paid work) and the subscript $j$ is used to denote the elements of the set of possible hours of household production that can be "bought off," i.e., replaced by market substitutes (e.g., by hiring a maid). The idea here is that the free time $(S)$ and income $(y)$ that may be obtained by the household depends on both the hours of employment and the hours of household production that they replace with market substitutes. Increasing the hours of employment reduces free time, but enhances the capacity to purchase market substitutes which, if feasible, increases free time.

Below, I denote the hours of employment as $L$, hours of household production replaced by market substitutes as $B$, the wage rate of the household as $w$, and the price of market substitute as $p$. In addition, I denote the time available to the household after setting aside (a) the minimum required amount of time for personal care and household production and (b) the amount of household production time required to subsist at the poverty-level of income, as $A$. This is the amount of time available to the household that can be split between employment and

${ }^{13}$ See Tania Burchardt (2008). 
free time. I denote the maximum number of hours of household production that can be replaced as $R$. The equations for free time and income are:

$$
\begin{gathered}
S_{i j}=A-L_{i}+B_{i j} \\
y_{i j}=w L_{i}-p B_{i j}
\end{gathered}
$$

Note that the potential interval for $B_{i j}$ is $\left(0, B_{i}^{\max }\right)$ and that $B_{i}^{\max }=\min \left(R, w L_{i} / p\right)$. The potential interval for $L_{i}$ is $\left(0, L^{\prime \prime}\right)$ where $L^{\prime \prime}$ is the maximum hours of employment that is assumed to be available. The set $\mathbb{Z}$ can be constructed for the household using the equations above for the specified intervals of $B$ and $L$.

\section{Time-income Capability Index}

The time-income capability index for the household is derived from the set of all "feasible" pairs of free time and income, $\mathbb{F}=\left\{S_{i j}, y_{i j}\right\}$. "Feasible" combinations are the combinations in which $S_{i j} \geq 0$ and $y_{i j} \geq y^{o}$, where $y^{o}$ is the income poverty threshold for the household. It should be noted that the first requirement, i.e., the nonnegativity of free time (or no timedeficit), implies that for the combinations in which $A<L_{i}$, the wage income of the household is sufficiently large to "buy out" the time-deficit $\left(A-L_{i}\right)$. If the household has only allocations (i.e., the division of hours between employment and free time) that yield below-poverty income then the time-income capability index is not defined for that household. ${ }^{14}$ Similarly, allocations that yield income below the poverty threshold do not enter into the determination of the index for the household that also happen to have feasible allocations.

The relative wage and time available to the household play a central role in constructing the feasible set, for which it is necessary to redefine the intervals of the values that $L$ and $B$ can take. The starting point for determining the minimum feasible hours of employment is the hours of employment that, given the wage, will be just sufficient to earn the poverty-level of income:

$$
L=\frac{y^{o}}{w}
$$

\footnotetext{
${ }^{14}$ This is conceptually distinct from the case when the index takes a value of zero that can occur for border-line allocations, i.e., allocations with zero free time or poverty-level income.
} 
If the time available for the household $(A)$ is equal to or greater than the hours of employment required to earn the poverty-level of income then $L^{o}$ would serve as the minimum feasible hours of employment. But, the hours of employment required to earn the poverty-level of income may exceed the time available to the household either because of its relatively low wage or relatively high burden of household production. In this case, the household would have to work beyond $L^{O}$ to earn a poverty-level of income. The extra hours required are:

$$
L^{\prime}=\frac{w\left(L^{o}-A\right)-p\left(L^{o}-A\right)}{w}
$$

The numerator of the equation is the difference between the amount that the household earns by working hours beyond what is available to it and the amount that the household has to spend on the market substitutes replacing the uncompensated portion of the household production foregone to facilitate the extra work. Dividing this difference by the wage yields the additional hours required, over and above $L^{o}$, to earn the poverty-level of income for the household that faces a time-deficit when working $L^{o}$ hours.

However, working the extra hours to attain the poverty threshold is not an option if the extra wage income is less than the extra costs of replacing the uncompensated portion of the household production, i.e., if the first term is less than the second term in the numerator of equation (34). This would be the case if the household wage is less than the price of the market substitutes. Under this scenario, the household with a time-deficit at $L^{o}$ hours will have no feasible allocations.

Thus, I can express the minimum hours of employment that would support the set of feasible allocations as:

$$
L_{i}^{\min } \begin{cases}=L^{o} & \text { if } A \geq L^{o} \\ =L^{o}+L^{\prime} & \text { if } A<L^{o} \text { and } w>p\end{cases}
$$

Turning to the maximum hours of employment, it is evident that if the minimum is given by the second line of the above equation, then the maximum would simply be the maximum hours of employment that is assumed to be available $\left(L^{\prime \prime}\right)$. On the other hand, if the minimum is $L^{o}$, then the maximum would depend on difference between the wage of the household and the price of the market substitutes. If the wage is less than the price then working beyond the time available 
will not be feasible because, as I discussed before, the extra income from working will not be sufficient to replace the uncompensated amount of the foregone household production.

Otherwise, the household can potentially work up to the maximum hours of employment that is assumed to be available.

Summarizing, there are four possible scenarios for the household, depending on its relative wage and available time:

Table 1: Possible scenarios for hours of employment

\begin{tabular}{|c|l|l|}
\hline Condition & \multicolumn{1}{|c|}{ Minimum } & \multicolumn{1}{c|}{ Maximum } \\
\hline$A \geq L^{o}$ and $w \geq p$ & $L^{o}$ & $L^{\prime}$ \\
\hline$A<L^{o}$ and $w \geq p$ & $L^{o}+L^{\prime}$ & $L^{\prime \prime}$ \\
\hline$A \geq L^{o}$ and $w<p$ & $L^{o}$ & $A$ \\
\hline$A<L^{o}$ and $w<p$ & No feasible hours of employment \\
\hline
\end{tabular}

${ }^{1}$ The feasible set is not defined for the household under the specified condition.

The quantity of time spent on household production that the market substitutes would replace $(B)$, and also would fall in a narrower interval under feasible allocations than under all possible allocations. For any given hours of employment (and the associated income), the minimum quantity of $B$ should rule out time-deficits:

$$
B_{i}^{\min } \begin{cases}=0 & \text { if } A-L_{i} \geq 0 \\ =\left|A-L_{i}\right| & \text { if } A-L_{i}<0\end{cases}
$$

The maximum value that $B$ can take has to be lowered to ensure that the household has enough income left to meet other, poverty-level expenses:

$$
B_{i}^{\max }=\min \left(R, \frac{w L_{i}-y^{o}}{p}\right)
$$

The set $F$ can be constructed for the household using the equations (31) and (32) above for the newly specified intervals of $L$ and $B$. The time-income capability index is defined as an area measure. Its derivation relies on the fact that for any given level of employment, the relationship between $y_{i j}$ and $S_{i j}$ is linear, with the slope equal to the replacement cost of household production. Replacing for $B_{i j}$ in (32) using (31) yields: 


$$
y_{i j}=w L_{i}-p\left(S_{i j}+L_{i}-A\right)
$$

The two ends of the line segment defined by equation (38) for a given level of $L$ is given by the pairs $\left(y_{i}^{\max }, S_{i}^{\min }\right)$ and $\left(y_{i}^{\min }, S_{i}^{\max }\right)$, calculated as follows:

$$
\begin{gathered}
y_{i}^{\max }=w L_{i}-p B_{i}^{\min } \\
S_{i}^{\min }=A-L_{i}+B_{i}^{\min } \\
y_{i}^{\min }=w L_{i}-p B_{i}^{\max } \\
S_{i}^{\max }=A-L_{i}+B_{i}^{\max }
\end{gathered}
$$

An illustration is shown below.

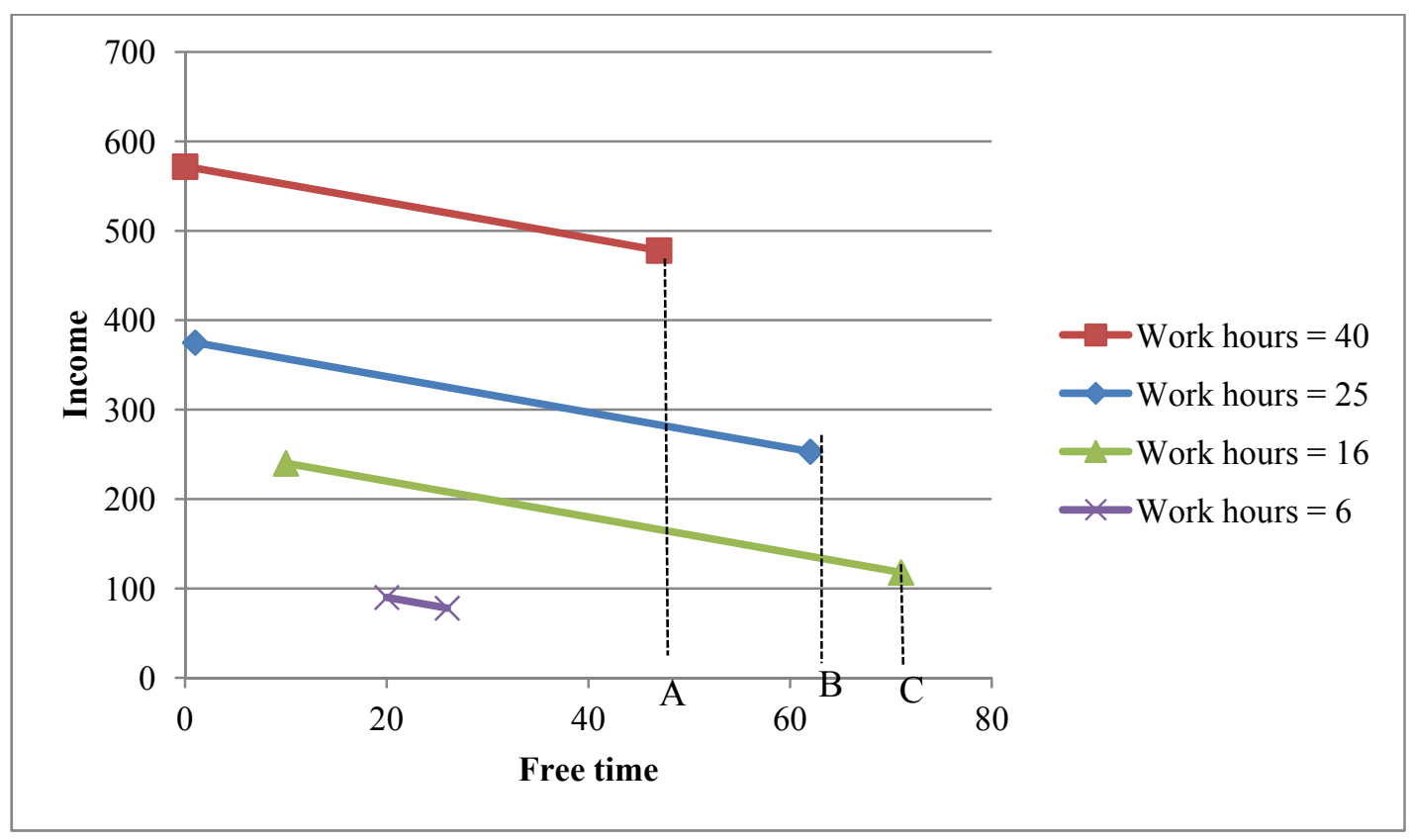

Figure 6 Example of time-income capability index

Once the set $\mathbb{F}$ has been computed, I order the pairs such that $S_{1}^{\max } \leq S_{2}^{\max } \leq S_{3}^{\max } \ldots . . \leq S_{k}^{\max }$ where the subscripts $1,2,3, \ldots . . k$ indicate various hours of employment in descending order, with 1 indicating the highest number of hours, 2 indicating the second highest number, and $k$ indicating the minimum. In order to avoid double counting the areas under the line segments, I omit from the set of ordered pairs, the pair in which the maximum free time is less than the maximum free time in the pairs that preceded it (e.g., the maximum free time-income pair 
associated with 6 hours of employment in Figure 4). ${ }^{15}$ Several such pairs may exist for the household. The time-income capability index is the sum of the non-overlapping areas under the line segments defined by equation (38) for various hours of employment, $1,2,3, \ldots . . k$ :

$$
T I=\int_{S_{1}^{\min }}^{S_{1}^{\max }} f\left(S_{1 j} \mid L_{1}\right) d S+\int_{S_{1}^{\max }}^{S_{2}^{\max }} f\left(S_{2 j} \mid L_{2}\right) d S+\ldots .+\int_{S_{k-1}^{\max }}^{S_{k}^{\max }} f\left(S_{k j} \mid L_{k}\right) d S
$$

where $f($.$) indicates the equation for the line segment. In the example shown in Figure 4, the$ limits of integration are given by $0, A, B$, and $C$.

${ }^{15}$ Alternatively, we could set their contribution to the index equal to zero. The equation below assumes this to be the case to simplify notation. 


\section{REFERENCES}

Antonopoulos, Rania and Emel Memiş. 2010. "Time and Poverty from a Developing Country Perspective.” Working Paper 600. Annandale-on-Hudson, NY: Levy Economics Institute of Bard College.

Bardasi, E. and Q. Wodon. 2009. "Working Long Hours and Having No Choice: Time Poverty in Guinea." Policy Research Working Paper Series 4961. The World Bank. Available at: http://ideas.repec.org/p/wbk/wbrwps/4961.html [Accessed May 13, 2010].

Becker, G. S. 1965. “A Theory of the Allocation of Time.” The Economic Journal 75 (299): 493-517.

Burchardt, T. 2008. "Time and Income Poverty." Center for Analysis of Social Exclusion Report 59, London School of Economics.

Citro, Constance F. and Robert T. Michael, (Eds.). 1995. Measuring Poverty: A New Approach. Washington, D.C.: National Academy Press.

Douthitt, Robin A. 2000. " “Time to do the Chores?” Factoring Household Production Needs into Measures of Poverty." Journal of Family and Economic Issues 21 (1): 7-22.

Goodin, R.E., Rice, J.M., Bittman, M., and P. Saunders. 2005. “The Time-Pressure Illusion: Discretionary Time vs. Free Time." Social Indicators Research 73: 43-70.

Gronau, Reuben. 1977. "Leisure, Home Production, and Work-the Theory of the Allocation of Time Revisited." The Journal of Political Economy 85 (6): 1099-1123.

Harvey, A. and A.K. Mukhopadhyay. 2007. "When Twenty-Four Hours is not Enough: TimePoverty of Working Parents.” Social Indicators Research (82): 57-77.

Quisumbing, A. R. 2004. Household Decisions, Gender, and Development: A Synthesis of Recent Research. International Food Policy Research Institute, Washington, D.C.

Robinson, J. P. and G. Godbey. 1997. Time for life: the surprising ways Americans use their time. Penn State Press.

Vickery, C. 1977. "The Time-Poor: A New Look at Poverty." The Journal of Human Resources $12(1): 27-48$. 